\title{
The ketogenic diet-defining a role in cancer therapy
}

\author{
Tan-Shalaby Jocelyn \\ ${ }^{1}$ Veteran Affairs Pittsburgh Healthcare System, USA \\ ${ }^{2}$ University of Pittsburgh School of Medicine, USA
}

\section{Cancer cell metabolism}

Cancer cells grow without boundaries and proliferate at high rates. Therefore, they require large amounts of energy. Unlike normal cells, cancer cells preferentially feed on glucose as a result of an overactive glycolytic process. While normal cells go through the process of glycolysis, the citric acid cycle, and the electron transport chain, cancer cells don't. Instead they favor glycolysis over oxidative phosphorylation even in the presence of oxygen. This is a phenomenon known as the "Warburg effect," which is seen even before the onset of hypoxia [1,2]. Proponents of the metabolic theory of cancer propose that defects in glycolytic enzymes as well as ketolytic enzymes within the mitochondria could be responsible for this effect.

Other scientists describe the origin of cancer as lying not within the cell but rather in the surrounding stroma, where cancer-associated fibroblasts also exhibit aerobic glycolysis [3]. These fibroblasts secrete hydrogen peroxide, which triggers oxidative stress. This stress transfers over to adjacent fibroblasts, which in turn boosts more aerobic glycolysis. The fibroblasts also produce lactate and ketones and transfer this energy to adjacent cancer cells. What we see as being visible on PET CT scanning with Fluoro-2-deoxy-D-glucose (F-2-DG), are actually cells of the tumor stroma rather than that of the cancer cell itself [3]. This energy transfer is what we call the "reverse Warburg effect."

Regardless of the location, there is increased lactic acid production, which tilts the tumor microenvironment towards a lower $\mathrm{pH}$. This acidic microenvironment can blunt the innate immune response towards cancer, accelerate tumor growth and promote cancer metastasis [4-6].

\section{Weight gain and cancer}

Cancer patients are commonly perceived to be in a constant catabolic state. As time progresses, weight loss accelerates, and cachexia develops despite aggressive caloric supplementation. This is a hallmark of terminal cancer. Weight loss is perceived as a harbinger of disease progression, and measures to thwart this process are often encouraged. Consequently, in oncology clinics there is a push to increase patients' caloric and carbohydrate intake in hopes of energizing the body to maximize its chances in the fight against cancer. In reality, there is little scientific data to support this approach. In fact, there is growing evidence that excessive weight gain may be in fact deleterious to cancer patients [7-9]

Obesity is linked to increased cancer incidence [8,9]. One reason behind this is a blunted body response to leptin. Leptin is a proinflammatory, appetite-decreasing hormone that arises from fatty tissue. Obese patients will eventually develop high leptin levels but later become unable to respond to its anorexic effects, hence becoming leptin resistant. They encounter difficulty in losing weight despite having high levels of leptin. Hyperleptinemia is seen in many cancers [10-
13]. Leptin can promote cancer by activating cancer stem cell division. It increases expression of nuclear factor kappa $\mathrm{B} / \mathrm{hypoxia}$ inducible factor alpha (NFkB /HIF-1 $\alpha$ ) and vascular endothelial growth factor (VEGF), which stimulates new blood vessel formation (angiogenesis), cell proliferation and inhibition of apoptosis. Indeed, targeting leptin signaling may be an attractive option for targeted cancer therapy [14].

Hyperinsulinemia is associated with obesity [15-17]. High carbohydrate consumers actively produce insulin in response to high blood glucose. Insulin allows glucose to enter cells where they can be converted into energy. There is more insulin receptor binding, which promotes mammalian target of rapamycin (mTOR) signaling, tumor growth and invasion. Over time, obese patients become insulin resistant and the resulting hyperinsulinemia can likewise be cancer promoting [10,11]. Carbohydrate-restricted diets can be of benefit by lowering blood glucose and decreasing insulin receptor binding.

High carbohydrate, nutrient poor diets can result in unhealthy weight gain and fuel cancer growth. A high fat, ketogenic diet could paradoxically reverse cancer associated cachexia. Tisdale et al found that a high fat diet could promote weight gain by increasing carcass mass and could reduce tumor size in a mouse model of colon cancer [18].

\section{Cancer epigenetics and the role of a ketogenic diet}

Tumor suppressors like p53 are highly mutated and hyperacetylated in many human tumors, enabling them to escape proteasome induced destruction, promote oncogene expression and develop resistance to chemotherapy [19]. Low-carbohydrate dieting can also down-regulate p53 mutants via de-acetylation and induce cell death. This blunting of mutant p53 expression, increases lifespan [20].

Ketogenesis occurs when the body produces ketones in response to fasting, starvation, or dietary carbohydrate restriction. By adopting a ketogenic diet, one slows down cancer growth via inhibition of IGF, PI3k/AKT/mTOR signaling pathways. Ketones by themselves can cause epigenetic changes that can synergize with existing cancer therapeutics [21-24].

Current data on humans and cancer are still very preliminary, consisting of mostly safety studies and case series [25-29]. Although efficacy in cancer cannot yet be determined, the existing body of evidence suggests that it is safe to follow. Given the expected lifespan

Correspondence to: Tan-Shalaby Jocelyn, Medical oncologist, Veteran Affairs Pittsburgh Healthcare System, USA, Clinical Assistant Professor of Medicine, University of Pittsburgh School of Medicine, USA, Tel: 4123606178, E-mail: jocelyn.tan@va.gov

Received: January 20, 2018; Accepted: February 06, 2018; Published: February 09,2018 
of advanced cancer patients, it is unlikely that long-term serious effects will be of issue. However, by itself, it is unlikely that the ketogenic diet can be used as a primary therapy against cancer. There might be more benefit for it as an adjunct to standard treatment such as biologics, targeted therapies or conventional chemotherapy [30].

\section{Future directions}

Targeted therapies are slowly populating the oncologic landscape. Immunohistochemical staining of ketolytic and glycolytic enzymes as well as identification of biomarkers (leptin and insulin) could be useful in the future. A ketogenic diet in addition to standard chemotherapy and/or radiation may improve tumor control and treatment outcomes, including quality of life. Increasing acceptance of this novel approach to cancer nutrition could hopefully define a new paradigm in cancer care.

\section{References}

1. Woolf EC, Scheck AC (2015) The ketogenic diet for the treatment of malignant glioma. J Lipid Res 56: 5-10. [Crossref]

2. Vidali S, Aminzadeh S, Lambert B, Rutherford T, Sperl W, et al. (2015) Mitochondria: The ketogenic diet - A metabolism-based therapy. Int J Biochem Cell Biol 63: 55-59. [Crossref]

3. Martinez-Outschoorn UE, Lin Z, Trimmer C, Flomenberg N, Wang C, et al. (2011) Cancer cells metabolically "fertilize" the tumor microenvironment with hydrogen peroxide, driving the Warburg effect: Implications for PET imaging of human tumors. Cell Cycle 10: 2504-2520. [Crossref]

4. Husain Z, Huang Y, Seth P, Sukhatme VP (2013) Tumor-derived lactate modifies antitumor immune response: effect on myeloid-derived suppressor cells and NK cells. J Immunol 191: 1486-1495. [Crossref]

5. Choi SYC, Collins CC, Gout PW, Wang Y (2013) Cancer-generated lactic acid: A regulatory, immunosuppressive metabolite? J Pathol 230: 350-355.

6. Robey IF, Martin NK (2011) Bicarbonate and dichloroacetate: evaluating pH altering therapies in a mouse model for metastatic breast cancer. BMC Cancer 11: 235.

7. Garofalo C, Surmacz E (2006) Leptin and cancer. J Cell Physiol 207: 12-22. [Crossref]

8. Giovannucci E (2001) Insulin, insulin-like growth factors and colon cancer: a review of the evidence. J Nutr 131: 3109S-3120S.

9. Giovannucci E (1995) Insulin and colon cancer. Cancer Causes Control 6: 164-179. [Crossref]

10. Amjadi F, Javanmard SH, Zarkesh-Esfahani H, Khazaei M, Narimani M (2011) Leptin promotes melanoma tumor growth in mice related to increasing circulating endothelial progenitor cells numbers and plasma NO production. J Exp Clin Cancer Res 30: 21. [Crossref]

11. Hussain SR, Naqvi H, Gupta S, Mahdi AA, Kumari P, et al. (2015) A study on oncogenic role of leptin and leptin receptor in oral squamous cell. Tumor Biol 36: 65156523. [Crossref]

12. Brandon EL, Gu JW, Cantwell L, He Z, Wallace G, et al. (2009) Obesity promotes melanoma tumor growth: Role of leptin. Cancer Biol Ther 8: 1871-1879. [Crossref]
13. Gonzalez-Perez RR, Xu Y, Guo S, Watters A, Zhou W, et al. (2010) Leptin upregulates VEGF in breast cancer via canonic and non-canonical signalling pathways and NF??B HIF-1?? activation. Cell Signal 22: 1350-1362. [Crossref]

14. Surmacz E (2007) Obesity hormone leptin: a new target in breast cancer? Breast Cancer Res 9: 301. [Crossref]

15. Gallagher EJ, LeRoith D (2011) Minireview: IGF, Insulin, and Cancer. Endocrinology 152: 2546-2551. [Crossref]

16. Clancy DJ, Gems D, Harshman LG, Oldham S, Stocker H, et al. (2001) Extension of life-span by loss of CHICO, a Drosophila insulin receptor substrate protein. Science 292: 104-106. [Crossref]

17. Arcidiacono B, Iiritano S, Nocera A, Possidente K, Nevolo MT, et al. (2012) Insulin resistance and cancer risk: An overview of the pathogenetic mechanisms. Exp Diabetes Res 2012: 789174. [Crossref]

18. Tisdale MJ, Brennan RA, Fearon KC (1987) Reduction of weight loss and tumour size in a cachexia model by a high fat diet. Br J Cancer 56: 39-43. [Crossref]

19. Muller PAJ, Vousden KH (2014) Mutant p53 in cancer: New functions and therapeutic opportunities. Cancer Cell 25: 304-317.

20. Rodriguez OC, Choudhury S, Kolukula V, Vietsch EE, Catania J, et al. (2012) Dietary downregulation of mutant p53 levels via glucose restriction: Mechanisms and implications for tumor therapy. Cell Cycle 11: 4436-4446. [Crossref]

21. Shimazu T, Hirschey MD, Newman J, He W, Shirakawa K, et al. (2013) Suppression of oxidative stress by $\beta$-hydroxybutyrate, an endogenous histone deacetylase inhibitor. Science 339: 211-214. [Crossref]

22. Davie JR (2003) Inhibition of histone deacetylase activity by butyrate. J Nutr 133 2485S-2493S. [Crossref]

23. Tan-Shalaby J (2017) Ketogenic diets and cancer: Emerging evidence. Fed Pract 34 $37 \mathrm{~S}-42 \mathrm{~S}$.

24. Tan-Shalaby JL, Carrick J, Edinger K, Genovese D, Liman AD, et al. (2016) Modified Atkins diet in advanced malignancies - final results of a safety and feasibility tria within the Veterans Affairs Pittsburgh Healthcare System. Nutr Metab (Lond) 13: 52. [Crossref]

25. Zuccoli G, Marcello N, Pisanello A, Servadei F, Vaccaro S, et al. (2010) Metabolic management of glioblastoma multiforme using standard therapy together with a restricted ketogenic diet: Case Report. Nutr Metab (Lond) 7: 33. [Crossref]

26. Fine EJ, Segal-Isaacson CJ, Feinman RD, Herszkopf S, Romano MC, et al. (2012) Targeting insulin inhibition as a metabolic therapy in advanced cancer: A pilot safety and feasibility dietary trial in 10 patients. Nutrition $28: 1028-1035$. [Crossref]

27. Nebeling LC, Miraldi F, Shurin SB, Lerner E (1995) Effects of a Ketogenic Diet on Tumor Metabolism and Nutritional Status in Pediatric Oncology Patients: Two Case Reports. J Am Coll Nutr 14: 202-208. [Crossref]

28. Chang HT, Olson LK, Schwartz KA (2013) Ketolytic and glycolytic enzymatic expression profiles in malignant gliomas: implication for ketogenic diet therapy. Nutr Metab (Lond) 10: 47. [Crossref]

29. Schmidt M, Pfetzer N, Schwab M, Strauss I, Kammerer U (2011) Effects of a ketogenic diet on the quality of life in 16 patients with advanced cancer: A pilot trial. Nutr Metab (Lond) 8: 54. [Crossref]

30. Newman JC, Verdin E (2014) Ketone bodies as signaling metabolites. Trends Endocrinol Metab 25: 42-52. [Crossref]

Copyright: (C2018 Tan-Shalaby J. This is an open-access article distributed under the terms of the Creative Commons Attribution License, which permits unrestricted use, distribution, and reproduction in any medium, provided the original author and source are credited. 